\title{
Prognostic Signification of Admission Hyperglycemia among Acute Stroke Patients in Intensive Care Units in Kinshasa, the Democratic Republic of the Congo
}

\author{
Josée K. Tshituta1, François B. Lepira ${ }^{2 *}$, François P. Kajingulu², Jean Robert R. Makulo, \\ Ernest K. Sumaili ${ }^{2}$, Pierre Z. Akilimali ${ }^{3}$, Aliocha N. Nkodila ${ }^{4}$, Freddy M. Mbuyi ${ }^{1}$, \\ Angèle I. Masewu' ${ }^{1}$, Stéphane Mutombo' ${ }^{1}$ Eric B. Amisi ${ }^{1}$, Jean Pierre M. Ilunga1, \\ Wilfrid B. Mbombo1, Patrick M. Mukuna1, Adolphe M. Kilembe1
}

\footnotetext{
${ }^{1}$ Department of Anesthesiology and Reanimation, University of Kinshasa Hospital, Kinshasa, The Democratic Republic of the Congo ${ }^{2}$ Division of Nephrology, Department of Internal Medicine, University of Kinshasa Hospital, Kinshasa, The Democratic Republic of the Congo

${ }^{3}$ Department of Epidemiology \& Biostatistics, Kinshasa School of Public Health, University of Kinshasa School of Medicine, Kinshasa, The Democratic Republic of the Congo

${ }^{4}$ Centre medical cite des Aveugles, Kinshasa, The Democratic Republic of the Congo

Email: *lepslepira@yahoo.fr, *fr.lepira@gmail.com
}

How to cite this paper: Tshituta, J.K., Lepira, F.B., Kajingulu, F.P., Makulo, J.R.R., Sumaili, E.K., Akilimali, P.Z., Nkodila, A.N., Mbuyi, F.M., Masewu, A.I., Mutombo, S., Amisi, E.B., Ilunga, J.P.M., Mbombo, W.B., Mukuna, P.M. and Kilembe, A.M. (2019) Prognostic Signification of Admission Hyperglycemia among Acute Stroke Patients in Intensive Care Units in Kinshasa, the Democratic Republic of the Congo. World Journal of Cardiovascular Diseases, 9, 665-680.

https://doi.org/10.4236/wjcd.2019.99060

Received: July 10, 2019

Accepted: September 7, 2019

Published: September 10, 2019

Copyright $\odot 2019$ by author(s) and Scientific Research Publishing Inc. This work is licensed under the Creative Commons Attribution International License (CC BY 4.0).

http://creativecommons.org/licenses/by/4.0/ c) (i) Open Access

\begin{abstract}
BACKGROUND AND AIM: Although admission hyperglycemia has been reported to be associated with unfavorable outcomes in acute stroke, little is known about this association in sub-Saharan Africa. Therefore, the aim of the present study was to assess the prognostic significance of admission hyperglycemia in the acute phase of stroke in Congolese patients. METHODS: In a multicenter prospective cohort study, consecutive patients with acute stroke were examined in 5 Emergency Rooms or Intensive Care Units of Kinshasa between July $15^{\text {th }}, 2017$ and March $15^{\text {th }}, 2018$. The severity of stroke was assessed at admission using the Glasgow Coma Scale. Stress hyperglycemia was defined as random blood glucose levels at admission $>140 \mathrm{mg} / \mathrm{dL}$ in patients without known type 2 diabetes mellitus (T2DM). The endpoint was 10-day all-cause in-hospital mortality. Survival (time-to-death) curves were built using the Kaplan Meier methods. Cox proportional analysis was used to identify predictors of 10-day all-cause in-hospital mortality. The predictive performance of blood glucose level to predict 10-day all-cause in-hospital mortality was assessed using ROC curve analysis. RESULTS: Out of 194 patients (mean age $58.7 \pm 13.1$ years; $64 \%$ males, $74.7 \%$ light to moderate stroke severity; $63.4 \%$ ischemic stroke) enrolled, 106 (54.6\%) had admission hyperglycemia
\end{abstract}


with 77 (72.6\%) having stress hyperglycemia. Ninety four deaths (48.5\%); mortality rate of 6 deaths per 100 person-days (95\%CI $2.7-9.3$ ) occurred during a median follow up time 6 (5 - 7) days equivalent to 1542 person-days. Independent predictors of 10-day all-cause in-hospital mortality were admission hyperglycemia regardless of diabetes status (aHR 3.77; 95\%CI 1.92 - 7.42; $\mathrm{p}<0.001)$, GCS $<8$ (aHR 2.87; 95\%CI $1.57-5.23 ; \mathrm{p}=0.001)$ and non-use of mechanical ventilation (aHR 1.97; 95\%CI $1.05-3.70 ; \mathrm{p}=0.034$ ). Blood glucose concentrations (AUC $0.743 ; 95 \% \mathrm{CI} 0.672$ - 0.814) had a better predictive performance for 10-day all-cause in-hospital mortality with an optimal value of $154 \mathrm{mg} / \mathrm{dL}$ (sensitivity $76.6 \%$ and specificity 70\%). CONCLUSION: More than half of critically ill stroke patients exhibit admission hyperglycemia that impacts negatively on their survival in the acute phase highlighting thus the need for a better blood glucose control to improve outcomes.

\section{Keywords}

Admission Hyperglycemia, Stroke, Prognostic Significance, Black Africans

\section{Introduction}

Stroke, a common clinical problem in emergency department, is associated with an increased risk of death, particularly in its acute phase highlighting thus the need for the search and control of potential predictors of mortality [1]. Among potential predictors, admission hyperglycemia has been reported to be a substantial contributor [1]. Indeed, increased admission blood glucose levels in acute stroke have been reported to be associated with longer in-hospital stay, increased costs and mortality [1] [2]. Hyperglycemia is found in more than half of patients with stroke with most of them not having a known history of diabetes mellitus [1] [2]. In some patients, hyperglycemia is considered a reflection of preexisting but unrecognized diabetes mellitus; however, more often, it is the result of an acute stress response, typically termed stress hyperglycemia [1] [2]. The toxic effects of hyperglycemia to the brain tissue are thought to rely upon several biochemical and hemodynamic mechanisms including the accumulation of lactic acid due to anaerobic metabolism, enhanced glutamate release, and increased cerebral edema [1] [2] [3]. Therefore, the evaluation of the relative contribution of admission hyperglycemia to the risk of death in the acute phase of stroke could help improve the outcome of patients with acute stroke [1] [2] [3].

In the Democratic Republic of the Congo (DRC), stroke is a common clinical finding in ICU and is associated with poor outcomes [4] [5] [6] [7] [8]. If the relationship between admission hyperglycemia and mortality has been already studied in stroke patients [5], it is not yet the case for those in the acute phase of stroke. Therefore, the aim of the present study was to assess the impact of admission hyperglycemia on outcome of stroke patients at the acute phase admit- 
ted in ICUs in Kinshasa, the capital City.

\section{Methods}

From July 15, 2017 to March 15, 2018, we conducted a multicenter prospective observational study searching for admission hyperglycemia and its impact on survival of patients admitted for acute stroke in 5 Intensive Care Units (ICUs, University of Kinshasa Hospital, Ngaliema Clinics, Mother \& Child Center Monkole, Biamba Marie Mutombo Hospital, Ngaliema Medical Center) in Kinshasa, the Capital City of the Democratic Republic of the Congo (DRC). Inclusion criteria were as follows: age $\geq 18$ years, stroke suspected clinically according to WHO recommendations [9] and confirmed by computerized tomography and informed consent. Were excluded patients without available blood glucose measurement or brain computerized tomography and those with transient ischemic attack. Data related to outcome were vital status and survival (time-to-death) during the acute phase of stroke defined as the first 10 days post-stroke. Demographic (age, gender, education level), past medical history and clinical characteristics were recorded at the time of enrollment. Initial stroke severity was evaluated on the first day of admission on the basis of the Glasgow Coma Scale (GCS) and classified as light to moderate (GCS $>8$ ) and severe (GCS $\leq 8$ ). Laboratory data on admission included non-fasting blood glucose, hemoglobin, hematocrit, white blood cells, blood urea nitrogen (BUN), serum creatinine, uric acid, cholesterol and its sub-fractions, serum triglycerides, serum electrolytes and were determined using usual techniques in the Central Laboratory of each participating ICU Admission random glucose was the first non-fasting plasma glucose measured using an enzymatic method at the central laboratory of each participating ICU. According to the American Diabetes Association (ADA) guidelines, hyperglycemia was defined as blood glucose $>7.8 \mathrm{mmol} / \mathrm{L}(>140$ $\mathrm{mg} / \mathrm{dL}$ ) and classified as acute (stress) hyperglycemia [random blood glucose $>$ $7.8 \mathrm{mmol} / \mathrm{L}(>140 \mathrm{mg} / \mathrm{dL})$ without evidence of previous diabetes] and chronic [in the absence of glycated hemoglobin, random blood glucose $>7.8 \mathrm{mmol} / \mathrm{L}$ $(>140 \mathrm{mg} / \mathrm{dL}$ ) with evidence of previous diabetes [10]. Hypertension was defined as a known previous diagnosis of hypertension or current use of antihypertensive drugs. Diabetes was defined as a history of known diabetes or current use of oral antidiabetic drugs or insulin.

\section{Statistical Analysis}

Baseline characteristics were summarized as mean (standard deviation) or median (interquartile range) for continuous variables and as number (\%) for categorical variables. Independent associations between baseline characteristics and hyperglycemia, defined as level of blood glucose $\geq 140 \mathrm{mg} / \mathrm{dL}$ were examined in multivariable logistic regression models with all significant baseline variables. Kaplan Meier method was used to describe survival over 10 days post stroke in the group as a whole and according to type of hyperglycemia, hyperglycemia and 
stroke type, hyperglycemia and stroke severity and insulin treatment status. Patients who survived at 10 days were censored. Difference between survival curves by admission hyperglycemia status was described using the Log-rank test. Cox proportional hazard modeling was used to assess independent predictors of 10-day all-cause in-hospital mortality with a special emphasis on admission hyperglycemia. Receiver operating characteristic (ROC) analysis was conducted for evaluating the predictive performance (Area Under the Curve) of the admission random glucose as a continuous variable to discriminate favorable and poor outcomes. P value $<0.05$ defined the level of statistical significance. The study was approved by the Ethical and Research Committee of Kinshasa School of Public Health and received the authorization of the Medical Staff of the different ICUs and Emergency Rooms involved in the present study.

\section{Results}

Sociodemographic and clinical characteristics of the study population as a whole and according to blood glucose status are summarized in Table 1. One hundred ninety four patients ( $64 \%$ males) with acute stroke were consecutively included in the present study. Their mean age was $58.7 \pm 13.1$ years with a half of them aged $\geq 60$ years. History of hypertension and diabetes was reported by 126 (64.9\%) and $32(16.5 \%)$ patients, respectively. In most of patients (75.3\%) care was supported by themselves or their family.

Admission hyperglycemia was observed in 106 (54.6\%) patients with the majority of them ( $\mathrm{n}=77 ; 72.6 \%)$ having stress hyperglycemia. Compared to patients without hyperglycemia, those with hyperglycemia had a significantly higher proportion $(55.7 \%$ vs $40.9 \% ; p=0.028)$ of patients aged $\geq 60$ years (Table $1)$.

Table 2 summarizes the biologic parameters of the study population as a whole and according to blood glucose status. In the entire group, average levels of blood glucose and eGFR were $182.4 \pm 27.5 \mathrm{mg} / \mathrm{dL}$ and $70.2 \pm 47.5 \mathrm{~mL} / \mathrm{min} / 1.73$ $\mathrm{m}^{2}$, respectively. Compared to patients without hyperglycemia, those with hyperglycemia had in average significantly lower eGFR levels (76.6 \pm 49.4 vs $57.0 \pm$ $40.4 \mathrm{~mL} / \mathrm{min} / 1.73 \mathrm{~m}^{2} ; \mathrm{p}=0.01$ ).

Stroke characteristics and treatment prescribed to the study population as a whole and according to blood glucose status are given in Table 3. In the whole group, ischemic and hemorrhagic strokes were observed in 115 (59.3\%) and 71 (36.6\%) patients, respectively. Symptoms most frequently reported were loss of consciousness (75.5\%), motor deficiency $(24.7 \%)$ and seizures $(13.9 \%)$. The average interval between stroke occurrence and medical admission was $30.1 \pm 3.0$ hours. Computerized brain tomography was performed within 6 - 12 hours, 12 24 hours and $\geq 24$ hours in 39 (17.9), 93 (42.7\%) and 88 (39.4\%) patients, respectively. GCS $\geq 8$ and $<8$ were observed in 145 (74.7\%) and 49 (25.3) patients, respectively. The average Sp02 was $90.8 \pm 9.6$ with the majority $(\mathrm{n}=150 ; 77.3 \%)$ having values $\geq 90 \%$. Antihypertensive (mainly nicardipine), anti-edematous 
Table 1. Sociodemographic and clinical characteristics of stroke patients as a whole and according to hyperglycemia status.

\begin{tabular}{|c|c|c|c|c|}
\hline Variables & $\begin{array}{c}\text { All } \\
\mathrm{n}=194\end{array}$ & $\begin{array}{c}\text { No Hyperglycemia } \\
n=88\end{array}$ & $\begin{array}{l}\text { Hyperglycemia } \\
\quad \mathrm{n}=106\end{array}$ & $\mathbf{P}$ \\
\hline Age, years & $58.7 \pm 13.1$ & $57.0 \pm 11.3$ & $60.1 \pm 14.3$ & $\begin{array}{l}0.099 \\
0.028\end{array}$ \\
\hline$<60, \mathrm{n}(\%)$ & $95(49)$ & $52(59.1)$ & $47(44.3)$ & \\
\hline$\geq 60, \mathrm{n}(\%)$ & $99(51)$ & $36(40.9)$ & $59(55.7)$ & \\
\hline Gender, n (\%) & & & & 0.497 \\
\hline Males & $129(64)$ & $58(65.9)$ & $71(67.0)$ & \\
\hline Females & $65(46)$ & $30(34.1)$ & $35(33.0)$ & \\
\hline Educational level, n (\%) & & & & 0.394 \\
\hline None & $23(11.9)$ & $12(13.6)$ & $11(10.4)$ & \\
\hline Primary/secondary & $99(51.0)$ & $39(44.3)$ & $60(54.6)$ & \\
\hline High & $72(37.1)$ & $37(42.0)$ & $35(33.0)$ & \\
\hline Care financial support, n (\%) & & & & 0.028 \\
\hline Patient/family & $146(75.3)$ & $60(68.2)$ & $86(81.1)$ & \\
\hline Employers/Insurance/public sector & $48(24.7)$ & $28(31.8)$ & $20(18.9)$ & \\
\hline Diabetes, n (\%) & $32(16.5)$ & $3(3.4)$ & $27(27.4)$ & $<0.001$ \\
\hline Diabetes duration, years & $7.7 \pm 2.3$ & $6.6 \pm 2.3$ & $7.8 \pm 2.2$ & 0.680 \\
\hline \multicolumn{5}{|l|}{ Type of hyperglycemia, n (\%) } \\
\hline Acute (stress) hyperglycemia & - & - & $77(72.6)$ & \\
\hline Chronic hyperglycemia & - & - & $29(27.4)$ & \\
\hline Hypertension, $\mathrm{n}(\%)$ & $126(64.9)$ & $55(62.5)$ & $71(67.0)$ & 0.308 \\
\hline Hypertension duration, years & $7.8 \pm 2.3$ & $7.1 \pm 2.8$ & $8.3 \pm 2.6$ & 0.214 \\
\hline Previous stroke, n (\%) & $38(19.6)$ & $18(20.5)$ & $20(18.9)$ & 0.853 \\
\hline Physically active, n (\%) & $14(7.2)$ & $8(9,1)$ & $6(5.7)$ & 0.260 \\
\hline Alcoholintake, n (\%) & $44(22.7)$ & $20(18.9)$ & $24(27.3)$ & 0.029 \\
\hline Smoking, n (\%) & $16(8.2)$ & $6(6.8)$ & $10(9.4)$ & 0.348 \\
\hline $\mathrm{SBP}, \mathrm{mmHg}$ & $168.1 \pm 37.5$ & $164.7 \pm 38.5$ & $171.3 \pm 36$ & 0.161 \\
\hline DBP, mmHg & $96.6 \pm 23.0$ & $93.9 \pm 23.2$ & $99.2 \pm 22.6$ & 0.064 \\
\hline MAP, mmHg & $120.4 \pm 26.1$ & $117.5 \pm 25.9$ & $123.3 \pm 26.1$ & 0.079 \\
\hline $\mathrm{PP}, \mathrm{mmHg}$ & $71.5 \pm 25.0$ & $70.9 \pm 28.3$ & $72.1 \pm 21.5$ & 0.687 \\
\hline HR, bpm & $92.5 \pm 23.9$ & $92.9 \pm 23.6$ & $92.1 \pm 24.3$ & 0.763 \\
\hline
\end{tabular}

Data are expressed as mean \pm standard deviation, absolute (n) and relative (\%) frequency. Abbreviations: SBP, systolic blood pressure DBP, diastolic blood pressure MAP, mean arterial blood pressure PP, pulse pressure $\mathrm{HR}$, heart rate bpm, beat per minute.

(mainly mannitol), anti-seizure (mainly phenobarbital), mechanical ventilation and insulin therapy were prescribed in 113 (58.2), 72 (37.1), 71 (36.5\%), 50 (25.7\%) and 33 (17\%) patients, respectively. Apart from insulin therapy, the 
Table 2. Biological parameters of stroke patients as a whole and according to hyperglycemia status.

\begin{tabular}{cccccc}
\hline Variables & $\mathbf{N}$ & $\begin{array}{c}\text { All } \\
\mathbf{n}=\mathbf{1 9 4}\end{array}$ & $\begin{array}{c}\text { No Hyperglycemia } \\
\mathbf{n}=\mathbf{8 8}\end{array}$ & $\begin{array}{c}\text { Hyperglycemia } \\
\mathbf{n}=106\end{array}$ & $\mathbf{P}$ \\
\hline Glucose, mg/Dl & 194 & $182.4 \pm 27.5$ & $196.0 \pm 23.9$ & $186.6 \pm 26.3$ & 0.343 \\
$\mathrm{WBC}, / \mathrm{LL}$ & 132 & $14206.5 \pm 269.6$ & $10502.9 \pm 242.8$ & $13051.9 \pm 225.8$ & 0.323 \\
$\mathrm{~N}, \%$ & 138 & $71.4 \pm 21.6$ & $69.9 \pm 19.5$ & $70.9 \pm 20.9$ & 0.659 \\
$\mathrm{~L}, \%$ & 132 & $21.6 \pm 15.9$ & $20.3 \pm 10.8$ & $21.2 \pm 14.4$ & 0.609 \\
Creatinine, mg/dL & 150 & $4.1 \pm 0.9$ & $3.6 \pm 0.7$ & $3.9 \pm 0.8$ & 0.681 \\
$\mathrm{eGFR}, \mathrm{mL} / \mathrm{min} / 1.73 \mathrm{~m}^{2}$ & 150 & $70.2 \pm 47.5$ & $76.6 \pm 49.4$ & $57.0 \pm 40.4$ & 0.017 \\
$\mathrm{BUN}, \mathrm{mg} / \mathrm{dL}$ & 150 & $58.6 \pm 5.9$ & $79.2 \pm 9.0$ & $64.9 \pm 7.1$ & 0.067 \\
$\mathrm{Uricacid} \mathrm{mg} / \mathrm{dL}$ & 22 & $7.6 \pm 1.6$ & $7.6 \pm 4.2$ & $7.6 \pm 3.7$ & 0.989 \\
$\mathrm{~K}^{+}, \mathrm{mEq} / \mathrm{L}$ & 110 & $4.2 \pm 0.6$ & $4,04 \pm 0.73$ & $4,2 \pm 0,7$ & 0.183 \\
$\mathrm{Na}^{+}, \mathrm{mEq} / \mathrm{L}$ & 89 & $138.5 \pm 9.7$ & $138.7 \pm 40.9$ & $134.1 \pm 25.7$ & 0.227 \\
$\mathrm{HCO}_{3}, \mathrm{mEq} / \mathrm{L}$ & 29 & $20.8 \pm 5.3$ & $22.1 \pm 5.1$ & $18.1 \pm 5.7$ & 0.074 \\
$\mathrm{Cl}^{-}, \mathrm{mEq} / \mathrm{L}$ & 38 & $102.7 \pm 9.4$ & $98.5 \pm 8.9$ & $104,6 \pm 9.9$ & 0.043 \\
$\mathrm{Calcium} \mathrm{mEq} / \mathrm{L}$ & 36 & $2.9 \pm 0.4$ & $3.02 \pm 03$ & $3.9 \pm 0.3$ & 0.298 \\
$\mathrm{Ca}^{++}, \mathrm{mEq} / \mathrm{L}$ & 10 & $1.7 \pm 0.6$ & $1.8 \pm 0.8$ & $1.3 \pm 0.1$ & 0.136 \\
\hline
\end{tabular}

Data are expressed as mean \pm standard deviation, absolute (n) and relative (\%) frequency. Abbreviations: WBC, white blood cell $\mathrm{N}$; neutrophils L, lymphocyte eGFR, estimated glomerular filtration rate $\mathrm{K}^{+}$potassium $\mathrm{Na}^{+}$; sodium $\mathrm{HCO}_{3}$, bicarbonates $\mathrm{Cl}^{-}$, chloride $\mathrm{Ca}^{++}$, ionized calcium.

Table 3. Stroke characteristics of the study population as a whole and according to hyperglycemia status.

\begin{tabular}{|c|c|c|c|c|}
\hline Variables & $\begin{array}{c}\text { All } \\
\mathrm{n}=194\end{array}$ & $\begin{array}{c}\text { No Hyperglycemia } \\
\mathbf{n}=\mathbf{8 8}\end{array}$ & $\begin{array}{l}\text { Hyperglycemia } \\
\mathrm{n}=106\end{array}$ & $\mathbf{P}$ \\
\hline \multicolumn{5}{|l|}{ Symptoms at admission, $\mathrm{n}(\%)$} \\
\hline Loss of consciousness & $146(75.3)$ & $61(69.3)$ & $85(80.2)$ & 0.057 \\
\hline Impotence & $48(24.7)$ & $25(28.4)$ & $23(21.7)$ & 0.181 \\
\hline Seizures & $27(13.9)$ & $15(17.0)$ & $12(11.3)$ & 0.174 \\
\hline Vomiting & $6(3.1)$ & $2(2.3)$ & $4(3.8)$ & 0.433 \\
\hline $\begin{array}{l}\text { Time Interval event-ICU } \\
\text { admission, hour }\end{array}$ & $30.1 \pm 3$ & $28.9 \pm 3.1$ & $31.1 \pm 3.2$ & 0.595 \\
\hline $\begin{array}{l}\text { Time interval event-brain CT scan, } \\
\mathrm{n}(\%)\end{array}$ & & & & 0.450 \\
\hline $6-12 \mathrm{~h}$ & $15(7.7)$ & $5(5.7)$ & $10(9.4)$ & \\
\hline $12-24 \mathrm{~h}$ & $93(47.9)$ & $40(45.5)$ & $53(50.0)$ & \\
\hline$\geq 24 \mathrm{~h}$ & $86(44.3)$ & $43(48.8)$ & $33(31.1)$ & \\
\hline Stroke type, n (\%) & & & & 0.115 \\
\hline Hemorrhagic & $71(36.6)$ & $39(44.3)$ & $32(30.2)$ & \\
\hline Ischemic & $115(59.3)$ & $49(55.6)$ & $69(65.1)$ & \\
\hline Others & $8(4.1)$ & $3(4.1)$ & $5(4.7)$ & \\
\hline
\end{tabular}




\section{Continued}

\begin{tabular}{|c|c|c|c|c|}
\hline Temperature, ${ }^{\circ} \mathrm{C}$ & $40.6 \pm 3,5$ & $40.7 \pm 6.6$ & $40,5 \pm 4,9$ & 0.971 \\
\hline Respiratory rate, $\mathrm{cpm}$ & $23.7 \pm 5.8$ & $23.5 \pm 5.8$ & $23.9 \pm 5.9$ & 0.531 \\
\hline \multirow[t]{2}{*}{ GCS } & $10.6 \pm 3.4$ & $11.5 \pm 3.0$ & $9.9 \pm 3.5$ & $<0.001$ \\
\hline & & & & $<0.001$ \\
\hline$<8$ & $49(25.3)$ & $10(11.4)$ & $39(36.8)$ & \\
\hline$\geq 8$ & $145(74.7)$ & $78(88.6)$ & $67(63.2)$ & \\
\hline \multirow[t]{2}{*}{ Sp02, \% } & $90,8 \pm 9.6$ & $10.5 \pm 3.5$ & $11.6 \pm 2.7$ & 0.183 \\
\hline & & & & 0.297 \\
\hline$<90$ & $44(22.7)$ & $22(25.0)$ & $22(20.8)$ & \\
\hline$\geq 90$ & $150(77.3)$ & $66(75.0)$ & $84(79.2)$ & \\
\hline Pupilla status, n (\%) & & & & 0.916 \\
\hline Bilateral myosis & $28(14.4)$ & $13(14.8)$ & $15(14.2)$ & \\
\hline Bilateral mydriasis & $22(11.3)$ & $11(12.5)$ & $11(10.4)$ & \\
\hline Motor deficiency, n (\%) & $120(61.9)$ & $57(64.8)$ & $63(59.4)$ & 0.270 \\
\hline \multicolumn{5}{|l|}{ Treatment, n (\%) } \\
\hline CCB (Nicardipine) & $113(58.2)$ & $64(72.7)$ & $70(66.0)$ & 0.199 \\
\hline Insulin & $43(22.2)$ & $0(0.0)$ & $43(40.6)$ & 0.007 \\
\hline Anti-seizure (Phenobarbital) & $71(36.5)$ & $32(36.4)$ & $39(36.8)$ & 0.536 \\
\hline Anti-edematous (Mannitol) & $72(37.1)$ & $26(29.5)$ & $46(43.4)$ & 0.003 \\
\hline Catecholamines & $33(17.0)$ & $9(10.2)$ & $24(22.6)$ & 0.057 \\
\hline Mechanical ventilation & $50(25.7)$ & $17(19.3)$ & $33(31.1)$ & 0.043 \\
\hline
\end{tabular}

Data are expressed as mean \pm standard deviation, absolute (n) and relative (\%) frequency. Abbreviations: $\mathrm{CT}$, computed tomography ${ }^{\circ} \mathrm{C}$, Celsius degree GCS, Glasgow coma scale Sp02, peripheral oxygen saturation $\mathrm{CCB}$, calcium channel blocker.

proportion of patients prescribed anti-edematous therapy was significantly higher (43.4 vs $29.5 \%$; $=0.003$ ) in patients with hyperglycemia compared to those without hyperglycemia (Table 3).

Among 194 study subjects, 94 deaths (48.5\%) equivalent to 6 deaths per 100 person-days (95\%CI 2.7 - 9.3) occurred within the first 10 days [median follow up time $6(5-7)$ days equivalent to 1542 person-days]. Of the 94 deaths, 73 (68.9\%) occurred among hyperglycemic patients $(\mathrm{n}=106)$ with $55(51.9 \%)$ and 18 (17.0\%) deaths among patients with stress and chronic hyperglycemia, respectively (Table 4). The survival in the whole group is depicted in Figure 1. Survival decreased overtime with values of $85.9 \%$ and $52.3 \%$ at days 2 and 10 after admission, respectively. With reference to blood glucose status (Figure 2), the survival was significantly better in patients without hyperglycemia $(\mathrm{p}<$ 0.001 ) in comparison to those with hyperglycemia. The survival was also better in stroke patients with GCS $\geq 8$ ( $\mathrm{p}<0.001)$ in comparison to those with stroke and GCS $<8$ (Figure 3). Hyperglycemic stroke patients without known diabetes 
Table 4. Outcomes in the study population as a whole.

\begin{tabular}{cccc}
\hline Blood glucose & $\mathrm{N}$ & \multicolumn{2}{c}{ Vital status } \\
\hline$<150 \mathrm{mg} / \mathrm{dL}, \mathrm{n}(\%)$ & 88 & $67(76.1)$ & Alive \\
$\geq 150 \mathrm{mg} / \mathrm{dL}, \mathrm{n}(\%)$ & 106 & $33(31.1)$ & $73(68.9)$ \\
- -Stress HG, $\mathrm{n}(\%)$ & 77 & $22(20.7)$ & $55(51.9)$ \\
- -ChronicHG, $\mathrm{n}(\%)$ & 29 & $11(10.4)$ & $18(17.0)$ \\
Total & 194 & $100(51.5)$ & $94(48.5)$
\end{tabular}

Data are expressed as absolute (n) and relative (in percent) frequency. Abbreviations: HG, hyperglycemia.

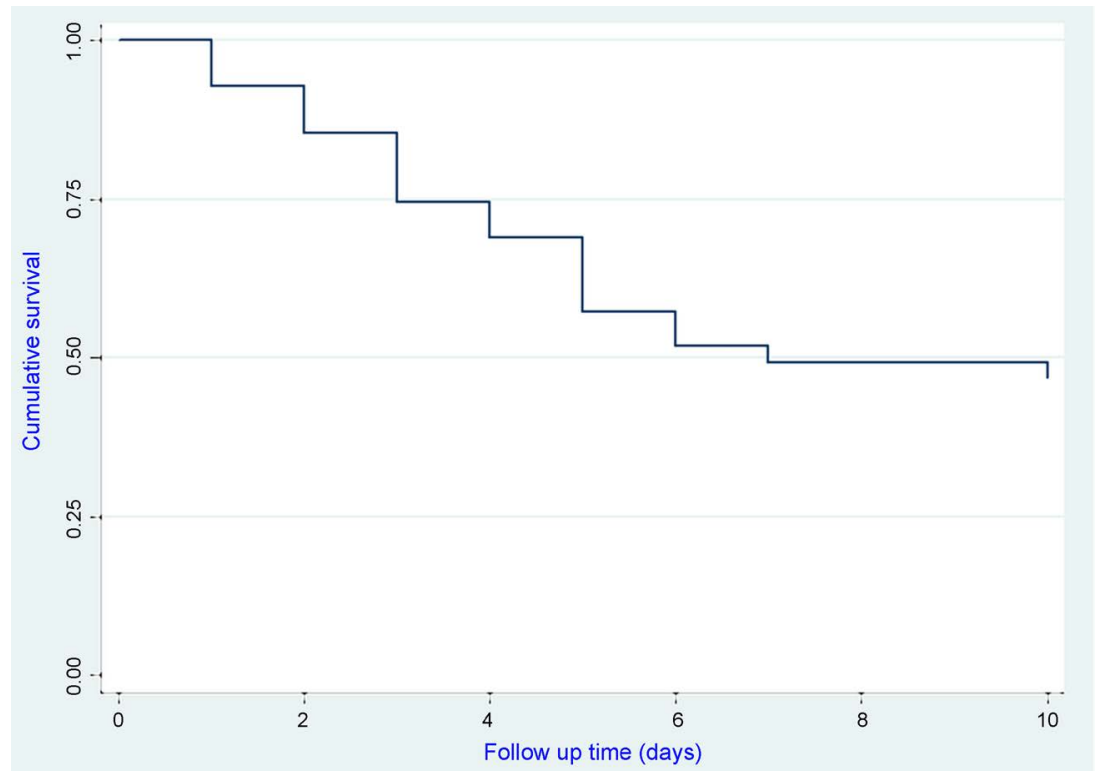

Figure 1. Survival curve of the study population as a whole.

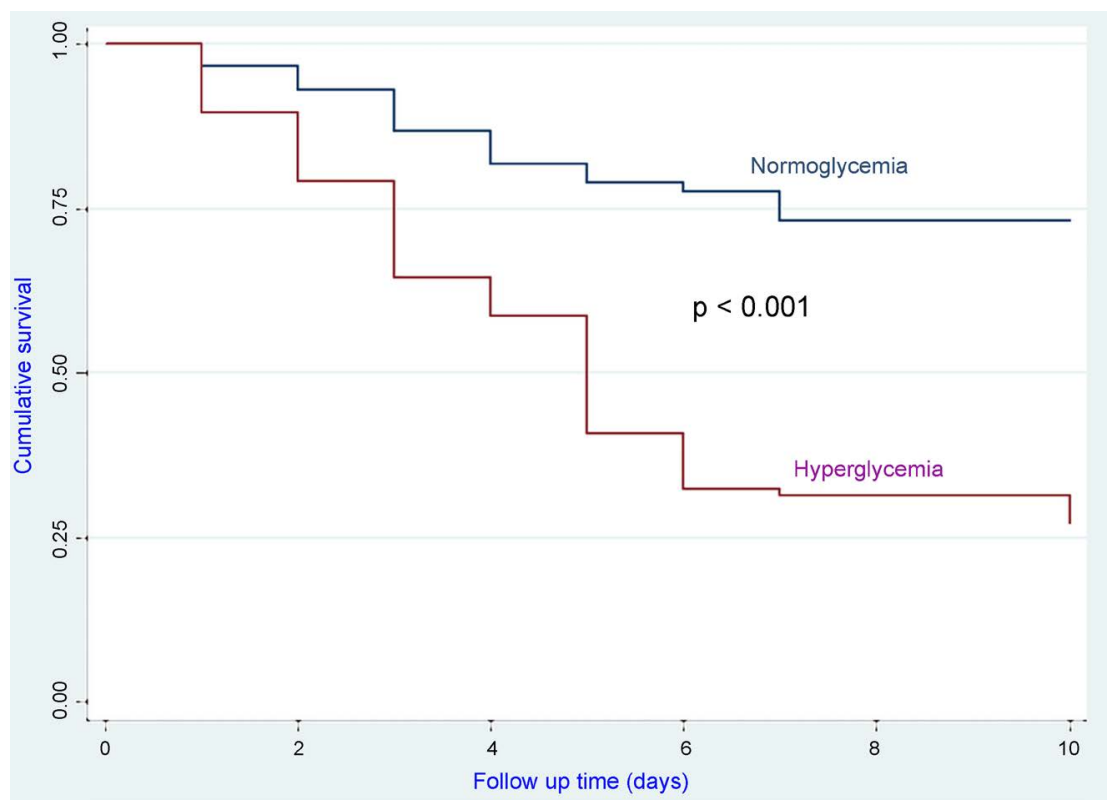

Figure 2. Survival curves of the study population according to blood glucose status. 


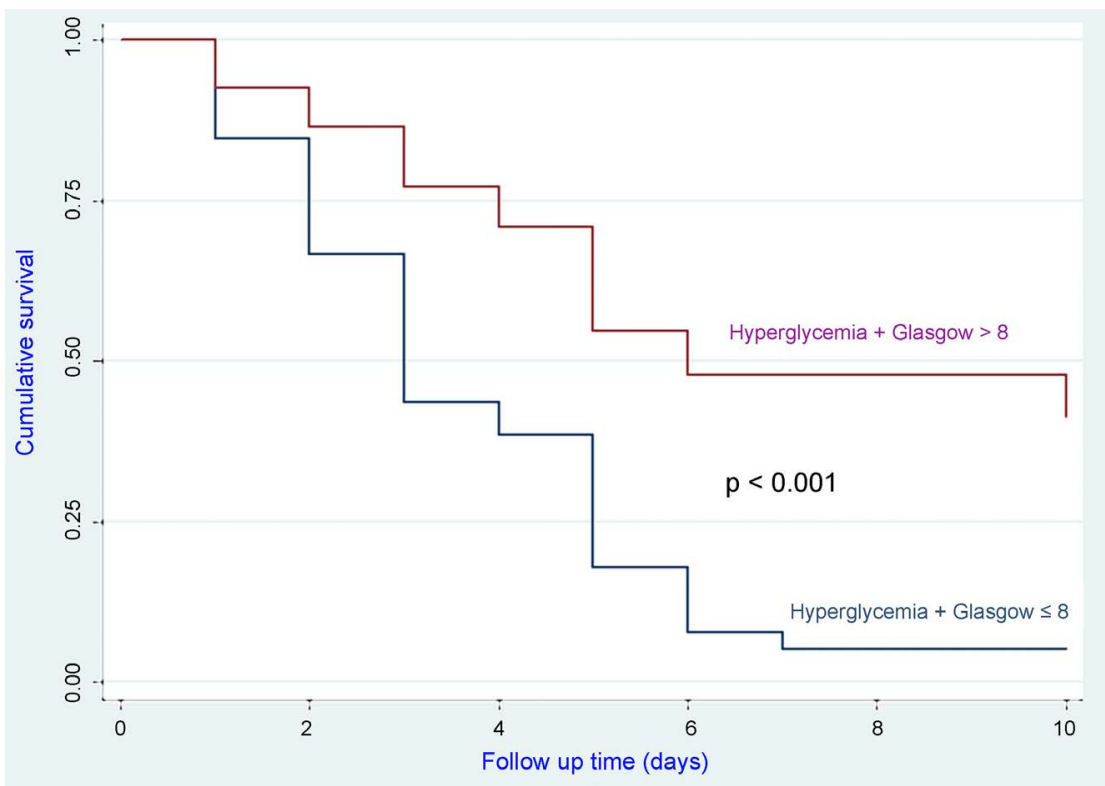

Figure 3. Survival curves of the study population according to blood glucose status and severity of stroke.

tended to have a worst survival than those with known diabetes (chronic hyperglycemia); however, the difference was not statistically significant.

Predictors of 10-day all-cause in-hospital mortality in the entire group are depicted in Table 4. In addition to stroke severity [GCS < 8 (aHR 2.87; 95\%CI 1.57 - 5.23; $\mathrm{p}=0.001$ ) ] and non-use of mechanical ventilation (aHR 1.97; 95\%CI 1.05 - 3.70; $\mathrm{p}=0.034$ ), admission hyperglycemia (aHR 3.77; 95\%CI $1.92-7.42 ; \mathrm{p}<$ 0.001 ) emerged as one of the main independent predictors of 10-day all-cause in-hospital mortality mortality.

The performance of blood glucose concentrations as a continuous variable in predicting 10-day all-cause in-hospital mortality is shown in Figure 4 . With an area under the curve (AUC) of 0.743 [IC 95\% (0.672 - 0.814)], blood glucose concentrations have shown a good performance in predicting 10-day all-cause in-hospital mortality in the present study. The cutoff value of admission blood glucose level with the highest sensitivity and specificity in predicting all-cause in-hospital mortality was $154 \mathrm{mg} / \mathrm{dL}$ (sensitivity $=76.6 \%$, specificity $=70.0 \%$ ).

\section{Discussion}

The main findings of the present study are as follows: first, survival was significantly worst in stroke patients with hyperglycemia and those with hyperglycemia and severe stroke; second, patients with stress hyperglycemia tended to experience a worst survival than those with chronic hyperglycemia (known diabetes); third, more than half of patients died in the present study with stroke severity, non-use of mechanical ventilation and hyperglycemia as the main independent predictors of 10-day all-cause in-hospital mortality in patients with predominantly mild to moderate stroke severity; fourth, admission blood glucose concentrations had a good predictive performance with $154 \mathrm{mg} / \mathrm{dL}$ as the cutoff 


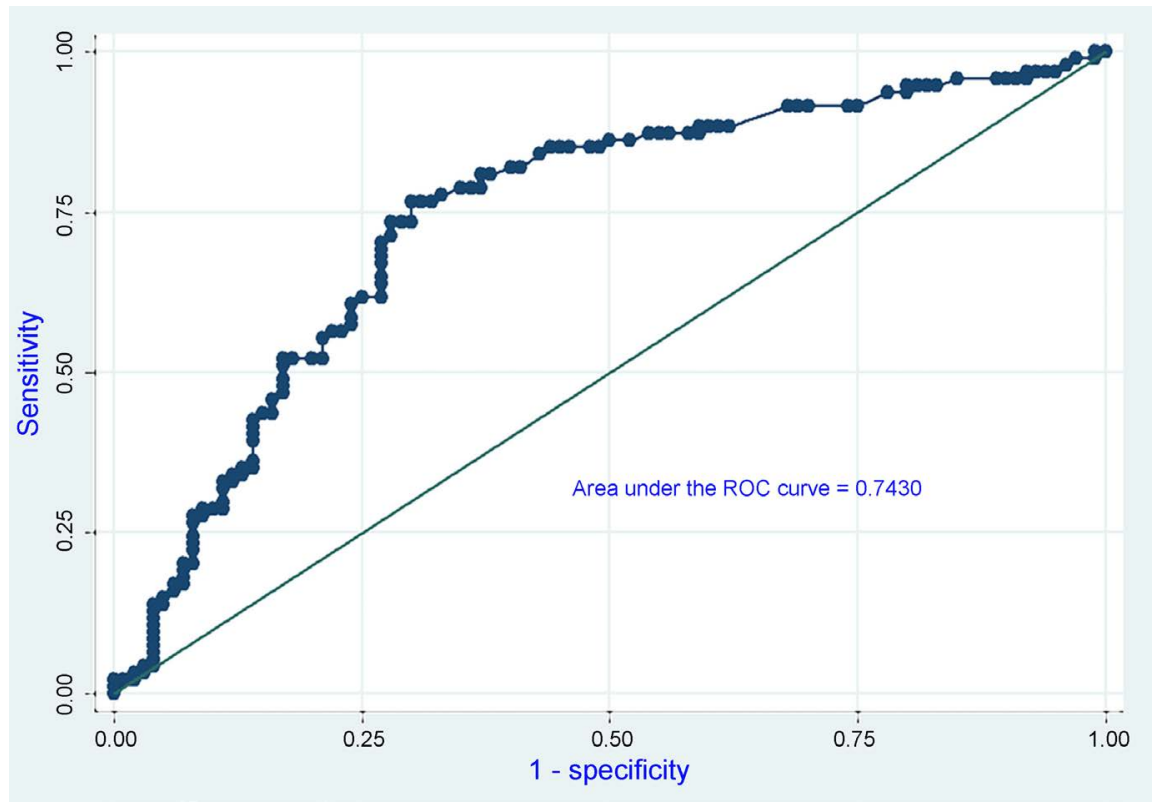

Figure 4. ROC curve of admission glucose for predicting all-cause in-hospital mortality.

value with the highest sensitivity and specificity in predicting 10-day all-cause in-hospital mortality.

Survival was worst in stroke patients with hyperglycemia than those without hyperglycemia. Our finding agrees with that of previous studies that reported hyperglycemia, acute or chronic, to be associated with increased mortality and worse clinical outcomes [1] [2] [3]. In this regard, Masrur et al. [1] found that blood glucose > $140 \mathrm{mg} / \mathrm{dL}$ (adjusted OR 1.68; 95\%CI 1.57 - 1.80) in patients with acute stroke was independently associated with in-hospital mortality. Similarly Marulaiah et al. [2] reported a significantly $(\mathrm{p}<0.0001)$ higher mortality rates in hyperglycemic than normoglycemic stroke patients.

Hyperglycemic patients with severe stroke had a poor survival than those with mild to moderate stroke. Our finding is consistent with that of previous reports of a major negative impact of initial stroke severity on the likelihood of death following acute stroke [11]. In this regard, Bhaskar et al. [12] observed that initial stroke severity (aOR 1.16; 95\%CI 1.12 - 1.20) independently predicted mortality following acute ischemic stroke. Similar finding has been also reported by Papagianni et al. [13] who found National Institute of Health Stroke Scale (NIHSS) at admission (RR 1.19; 95\%CI $1.14-1.23 ; \mathrm{p}<0.001$ ) to be one of the main predictors of in-hospital mortality after ischemic stroke. In accordance with the abovementioned studies, Hong et al. [14] and Fonarow et al. [15] reported the predominance of greater initial stroke severity over all other factors for the worse outcome of acute stroke.

Hyperglycemic stroke patients without known diabetes (stress hyperglycemia) tended to experience a worst survival than those with known diabetes (chronic hyperglycemia) in the present study. Our finding agrees with previous reports by Capes et al. [16] and others [3] [17] of a relatively worse prognosis in hypergly- 
cemic patients without a prior history of diabetes compared to those with known diabetes. The apparent better survival seen in diabetic patients could be explained by the fact that preconditioning by chronic elevation in blood glucose levels may offset stress-induced sympathetic autonomic nervous system activation and subsequent adverse metabolic effects. Moreover, some medications such as antihypertensive drugs (inhibitors of renin angiotensin system, calcium channel blockers, beta- blockers), statins and antiplatelet drugs that diabetics are frequently prescribed may confer a protective effect against acute stress response [11] [16] [17] [18]. This differential impact of hyperglycemia on outcomes among stroke patients without and with a history of diabetes has been illustrated by Snarska et al. [19] who reported a cut-off value of blood glucose concentrations for predicting death of $113.5 \mathrm{mg} / \mathrm{dL}$ and $210.5 \mathrm{mg} / \mathrm{dL}$ among stroke patients without and with a history of diabetes, respectively.

Nearly half and more than half of deaths occurred in the whole group and the hyperglycemic subgroup, respectively. This observed mortality is somewhat similar to that of $44 \%$ and $47 \%$ reported ten years ago by Longo-Mbenza et al. [20] in the same setting and by Kuate et al. [21] at Douala in Cameroon, respectively. However, it is quite higher than that found by most other studies from sub-Saharan African countries [22]-[28]. The differences in the number of deaths between studies and countries could be explained by the differences in public health response against stroke, access to health services, treatment options, population studied, sample size and study design, statistical methods and threshold used to define hyperglycemia [24].

Stroke severity and hyperglycemia were the main predictors of 10-day all-cause in-hospital mortality in the present study. Our finding agrees with that of previous studies from sub-Saharan African countries reporting stroke severity or need of cardio-pulmonary resuscitation and hyperglycemia as main predictors of poor outcomes [20] [27] [28] [29] [30] and adds insights to the relative influence of stroke severity and hyperglycemia on clinical and neurological outcomes following stroke occurrence [31]. Even though most studies have shown that hyperglycemia at admission confers a worse prognosis following acute stroke, it is still unclear whether it only reflects stroke severity or it is directly associated with outcomes [2] [32]. Although some studies have suggested acute hyperglycemia as a marker of stroke severity, the majority of basic science research support the theory that hyperglycemia at admission leads to worsened outcomes through its direct toxic effects on the brain tissue (in particular to the vulnerable ischemic penumbra) possibly because of the accumulation of lactic acid secondary to anaerobic metabolism, enhanced excitatory neurotransmitter (glutamate, aspartate) release, and increased cerebral edema [2] [33]. Hyperglycemia has been also reported to promote oxidative stress, inflammation and neuronal apoptosis, alter cerebral microcirculation with subsequent blood-brain barrier disruption [33] [34] [35]. All these biochemical, molecular and metabolic changes translate into infarct volume growth and hemorrhagic transformation, 
decreased recanalization rates, hematoma and peri-hematoma edema size growth, increased risk of poor neurological outcome and mortality [3] [18] [35]. The finding of hyperglycemia as a predictor of mortality independent of stroke severity does suggest that hyperglycemia in the present study could have direct toxic effects on the brain tissue [33]. Despite the lack of randomized evidence on the beneficial effects of insulin therapy in acute stroke, our finding does support recommendations from current guidelines for good glycemic control in patients with acute stroke [36].

Admission blood glucose concentrations had a good predictive performance in predicting 10-day all-cause in-hospital mortality in the present study. The good performance of random blood glucose concentrations in predicting poor outcomes in acute stroke has been already reported. Similar to our finding, Sung et al. [3] reported in a study on the predictive performance of various glycemic indices that random blood glucose concentrations (AUC 0.564; 95\%CI 0.519 $0.609 ; \mathrm{p}=0.026$ ) and fasting plasma glucose (AUC $0.598 ; 95 \% \mathrm{CI} 0.553-0.642 ; \mathrm{p}$ $=0.001$ ) were significant predictors of poor outcomes in acute ischemic stroke. Similar finding has been reported by Snarska et al. [19] who found in hyperglycemic patients with and without a history of diabetes that the area under the curve of admission blood glucose was significantly higher than 0.50 indicating the good predictive value of this parameter for predicting stroke outcome.

We found $154 \mathrm{mg} / \mathrm{L}$ as the blood glucose concentration value with the highest sensitivity and specificity in predicting all-cause in-hospital mortality. Similar to our finding, Nardi et al. [37] using ROC analysis found blood glucose concentration $\geq 143 \mathrm{mg} / \mathrm{dl}$ as the only significant predictive value for 72 -hour fatality (sensitivity $88 \%$ and specificity $62 \%$ ), especially in non-diabetics (sensitivity $88 \%$ and specificity 62\%). In contrast to Nardi et al. study, Sung et al. [3] reported $127 \mathrm{mg} / \mathrm{dL}$ (sensitivity $74.6 \%$, specificity $39.3 \%$ ) as the value with the highest sensitivity and specificity in predicting outcomes in acute stroke. The differences in optimal blood glucose levels between the studies could be explained by differences in criteria used to define hyperglycemia and to include patients in the study as well as the treatment prescribed to patients. The exact threshold at which elevated blood glucose levels are associated with increased risk of poor outcomes is not yet well established. Thus, the clinical guidelines published by American Heart Association/American Stroke Association and European Stroke Organization recommend that glycemic levels of patients with acute stroke be maintained below $180 \mathrm{mg} / \mathrm{dl}$. This cutoff based on the consensus of Experts does not support maintaining blood glucose concentrations at a specific level improves outcomes [36] [38]. Thus, ROC analysis which enables the comparison of the predictive performance of various glycemic indices and provides information on sensitivity and specificity (not afforded by consensus threshold) could be an alternative in identifying the optimal value of blood glucose for the prediction of outcomes in acute stroke [3].

The interpretation of the results of the present study should take into account 
some limitations. First, the small sample size did not allow sufficient power to statistical tests to identify association between variables of interest. Second, single measurement of blood glucose concentration could lead to regression dilution bias and misclassification of patients. Third, the lack of glycated hemoglobin measurements could have underestimated the frequency of chronic hyperglycemia.

\section{Conclusion}

Admission hyperglycemia with an optimal value of $154 \mathrm{mg} / \mathrm{dL}$ for predicting 10-day all-cause mortality emerged in the present study as an independent predictor of in-hospital mortality highlighting thus the need in accordance with guidelines recommendations for a better glucose control to improve acute stroke outcomes.

\section{Acknowledgements}

The authors gratefully thank the medical staff of all the participating ICUs (Dr Alphonse Mosolo Ganzele, Head of Monkole Hospital; Dr Richard Mvuala, Head of Ngaliema Clinics ICU; Rigo Shamamba Kusimwa, Head of Ngaliema Medical Center ICU) for their outstanding help during the conduct of the present study. The authors would like also thank all the participants and their parents who facilitate by their informed consent the implementation of the present study.

\section{Authors Contribution}

JKT collected data, participated in data analysis and reviewed the manuscript. FBl conceived the study, participated in data analysis and drafted the manuscript. FPK participated in data analysis and reviewed the manuscript. JRRM participated in statistical analysis of data and reviewed the manuscript. EKS participated in statistical analysis of data and reviewed the manuscript. PZA participated in statistical analysis of data and reviewed the manuscript. ANN participated in statistical analysis of data and reviewed the manuscript. FMM reviewed the manuscript. AIM reviewed the manuscript. SM reviewed the manuscript. EBA reviewed the manuscript. JPMI reviewed the manuscript. WDM reviewed the manuscript. PMM revised the manuscript. AMK participated in study conception and revised the manuscript.

\section{Conflicts of Interest}

No conflict.

\section{References}

[1] Masrur, S., Cox, M., Bhatt, D., et al. (2015) Association of Acute and Chronic Hyperglycemia with Acute Ischemique Stroke Outcomes Post-Thrombolysis: Findings from Get with the Guidelines-Stroke. Journal of the American Heart Associa- 
tion, 4, e002193. https://doi.org/10.1161/JAHA.115.002193

[2] Marulaiah, S., Reddy, M., Basavegowda, M., et al. (2017) Admission Hyperglycemia an Independent Predictor of Outcome in Acute Ischemic Stroke: A Longitudinal Study from a Tertiary Care Hospital in South India. Nigerian Journal of Clinical Practice, 20, 573-580. https://doi.org/10.4103/1119-3077.206368

[3] Sung, J., Chen, C., Hsieh, Y., et al. (2017) Comparison of Admission Random Glucose, Fasting Glucose, and Glycated Hemoglobin in Predicting the Neurological Outcome of Acute Ischemic Stroke: A Retrospective Study. PeerJ, 5, e2948. https://doi.org/10.7717/peerj.2948

[4] Mboliasa, I., Lepira, B., Makulo, R., et al. (2015) Profil épidémiologique et clinique des urgences cardiovasculaires admises aux soins intensifs de médecine interne des Cliniques Universitaires de Kinshasa. Annals of African Medicine, 8, 1-6.

[5] Lepira, F.B., M’Buyamba, K., Kayembe, P.K., et al. (2010) Hyperglycemia and in Hospital Mortality in Patients with Acute Stroke in Mbuji-Mayi, the Democratic Republic of Congo. Annals of African Medicine, 3, 469-477.

[6] M’Buyamba-Kabangu, J.R., Biswika, R.T., Thijs, L., et al. (2009) In-Hospital Mortality among Black Patients Admitted for Hypertension-Related Disorders in Mbuji Mayi, Congo. American Journal of Hypertension, 22, 643-648.

https://doi.org/10.1038/ajh.2009.47

[7] Katchunga, B.P. and Kayembe, N. (2007) Morbi-mortalité des AVC en unité des soins intensifs de la Ville Kinshasa. Congo Médical, 4, 1-5.

[8] Mbala, M. (1994) Morbidité et mortalité hospitalières de l'adulte zaïrois. Panorama Médical, 5, 234-237.

[9] WHO MONICA Project Investigators (2002) The World Health Organization (WHO) Report: 2002: Reducing Risks, Promoting Healthy Life. WHO, GGeneva.

[10] American Diabetes Association (2014) Diagnosis and Classification of Diabetes Mellitus. Diabetes Care, 37, S81-S90. https://doi.org/10.2337/dc14-S081

[11] Ntaios, G., Egli, M., Faouzi, M., et al. (2010) J-Shaped Association between Serum Glucose and Functional Outcome in Acute Ischemic Stroke. Stroke, 41, 2366-2370. https://doi.org/10.1161/STROKEAHA.110.592170

[12] Bhaskar, S., Stanwell, P., Bivard, A., Spratt, N., Walker, R., Kitsos, G.H., et al. (2017) The Influence of Initial Stroke Severity on Mortality, Overall Functional Outcome and in-Hospital Placement at 90 Days Following Acute Ischemic Stroke: A Tertiary Hospital Stroke Register Study. Neurology India, 65, 1252-1259. https://doi.org/10.4103/0028-3886.217947

[13] Papagianni, M., Tziomalos, K., Kostaki, S., Angelopoulou, S.M., Christou, K., Bouziano, S.D., et al. (2018) Treatment with Mannitol Is Associated with Increased Risk for in-Hospital Mortality in Patients with Acute Ischemic Stroke and Cerebral Edema. American Journal of Cardiovascular Drugs, 18, 397-403.

[14] Hong, K.S., Lee, J., Bae, H.J., Lee, J.S., Kang, D.W., Yu, K.H., et al. (2013) Greater Stroke Severity Predominates over All Other Factors for the Worse Outcome of Cardioembolic Stroke. Journal of Stroke and Cerebrovascular Diseases, 22, e373-e380. https://doi.org/10.1016/j.jstrokecerebrovasdis.2013.04.008

[15] Fonarow, G.C., Saver, J.L., Smith, E.E., Broderick, J.P., Kleindorfer, D.O., Scco, R.L., et al. (2012) Relationship of National Institutes of Health Stroke Scale to 30-Day Mortality in Medicare Beneficiaries with Acute Ischemic Stroke. Journal of the American Heart Association, 1, 42-50. https://doi.org/10.1161/JAHA.111.000034

[16] Capes, S.E., Hunt, D., Malmberg, K., et al. (2001) Stress Hyperglycemia and Prog- 
nosis of Stroke in Nondiabetic and Diabetic Patients: A Systematic Review. Stroke, 32, 2426-2432. https://doi.org/10.1161/hs1001.096194

[17] Stead, L.G., Gilmore, R.M., Fernanda, B.M., et al. (2009) Hyperglycemia as an Independent Predictor of Worse Outcome in Non-Diabetic Patients Presenting with Acute Ischemic Stroke. Neurocritical Care, 10, 181-186. https://doi.org/10.1007/s12028-008-9080-0

[18] Raghavendra, P., Sandeep, R.A., Prabhakar, K., et al. (2016) Stress Hyperglycemia as a Prognostic Marker in Acute Ischaemic Stroke. European Journal of Pharmaceutical and Medical Research, 3, 247-256.

[19] Snarska, K.K., Bachorzewska-Gajewska, H., Kapica-Topezewska, K., et al. (2017) Hyperglycemia and Diabetes Have Different Impacts on Outcome in Ischemic and Hemorrhagic Stroke? Archives of Medical Science, 13, 100-108. https://doi.org/10.5114/aoms.2016.61009

[20] Longo-Mbenza, B., Lelo Tshinkwela, M. and Mbuilu Pukuta, J. (2008) Rates and Predictors of Stroke-Associated Case Fatality in Black Central African Patients. The Cardiovascular Journal of Africa, 19, 72-76.

[21] Kuate, T.C., Mapoure, N.Y., Gopdjim, M.L., et al. (2016) Mortalité par Accident vasculaire cérébral et ses déterminants dans un hôpital de référence de Douala (Cameroun). Health Sciences and Diseases, 17, 1-6.

[22] Owolabi, M.O., Sarfo, F., Akinyemi, R., et al. (2018) Dominant Modifiable Risk Factors for Stroke in Ghana and Nigeria (SIREN): A Case-Control Study. The Lancet Global Health, 6, e436-e446. https://doi.org/10.1016/S2214-109X(18)30002-0

[23] Ekeh, B., Ogunniyi, A., Isamade, E. and Ekrikpo, U. (2015) Stroke Mortality and Its Predictors in a Nigerian Teaching Hospital. African Health Sciences, 15, 74-81. https://doi.org/10.4314/ahs.v15i1.10

[24] Adeloye, D. (2014) An Estimate of the Incidence and Prevalence of Stroke in Africa: A Systematic Review and Meta-Analysis. PLoS ONE, 9, e100724. https://doi.org/10.1371/journal.pone.0100724.t001

[25] Desalu, O.O., Wahab, K.W., Fawale, B., et al. (2011) A Review of Stroke Admissions at a Tertiary Hospital in Rural Southwestern Nigeria. Annals of African Medicine, 10, 80-85. https://doi.org/10.4103/1596-3519.82061

[26] Ogbu, U.C., Westert, G.P., Slobbe, L.C.J., Arah, O.A. and Stronks, K. (2011) A Multifaceted Look at Time of Admission and Its Impact on Case-Fatality among a Cohort of Ischaemic Stroke Patients. Journal of Neurology, Neurosurgery \& Psychiatry, 82, 8-13. https://doi.org/10.1136/jnnp.2009.202176

[27] Wahab, K.W. (2008) The Burden of Stroke in Nigeria. International Journal of Stroke, 3, 290-292. https://doi.org/10.1111/j.1747-4949.2008.00217.x

[28] Toure, K., Diagne, B.L., Seck, B.L., et al. (2010) Predictors of Stroke Mortality at the Department of Neurology, Fann University Teaching Hospital, Dakar-Senegal. African Journal of Neurological Sciences, 24, 325-334.

[29] Gomes, J., Damasceno, A., Carrilho, C., et al. (2013) Determinants of Early Case-Fatality among Stroke Patients in Maputo, Mozambique and Impact of in-Hospital Complications. International Journal of Stroke, 8, 69-75. https://doi.org/10.1111/j.1747-4949.2012.00957.x

[30] Mapoure, N.Y., Tchaleu, C.B., Mbatchou, H.B., et al. (2014) Predictors of in-Hospital Mortality for Stroke in Douala, Cameroon. Stroke Research and Treatment, 2014, Article ID: 681209. https://doi.org/10.1155/2014/681209

[31] Yao, M., Ni, J., Zhou, L., Peng, B., Zhu, Y., Cui, L., et al. (2016) Elevated Fasting 
Blood Glucose Is Predictive of poor out come in Non-Diabetic Stroke Patients: A Sub-Group Analysis of SMART. China. PLoS ONE, 11, e0160674.

https://doi.org/10.1371/journal.pone.0160674

[32] Tziomalos, K., Dimitriou, P., Bouziana, S.D., et al. (2017) Stress Hyperglycemia and Acute Ischemic Stroke in-Hospital Outcome. Metabolism, 67, 99-105. https://doi.org/10.1016/j.metabol.2016.11.011

[33] Saxena, A., Craig, S., Anderson, C.S., Wang, X., et al. (2016) Prognostic Significance of Hyperglycemia in Acute Intracerebral Hemorrhage: The INTERACT2 Study. Stroke, 47, 682-688. https://doi.org/10.1161/STROKEAHA.115.011627

[34] González-Moreno, E.I., Cámara-Lemarroy, C.R., González-González, J.G. and Góngora-Rivera, F. (2014) Glycemic Variability and Acute Ischemic Stroke: The Missing Link? Translational Stroke Research, 5, 638-646.

https://doi.org/10.1007/s12975-014-0365-7

[35] Zhao, Z., Hu, J., Gao, X., et al. (2017) Hyperglycemia via Activation of Thromboxane A2 Receptor Impairs the Integrity and Function of Blood-Brain Barrier in Microvascular Endothelial Cells. Oncotarget, 8, 30030-30038.

https://doi.org/10.18632/oncotarget.16273

[36] European Stroke Organization Executive Committee (ESOW) (2008) Guidelines for Management of Ischaemic Stroke and Transient Ischaemic Attack 2008. Cerebrovascular Diseases, 25, 457507. https://doi.org/10.1159/000131083

[37] Nardi, K., Milla, P., Eusebi, P., et al. (2012) Predictive Value of Admission Blood Glucose Level and Short-Term Mortality in Acute Cerebral Ischemia. Journal of Diabetes and Its Complications, 26, 70-76. https://doi.org/10.1016/j.jdiacomp.2012.03.001

[38] Jauch, E.C., Saver, J.L., Adams Jr., H.P., et al. (2013) Guidelines for the Early Management of Patients with Acute Ischemic Stroke: A Guideline for Health Care Professionals from the American Heart Association/American Stroke Association. Stroke, 44, 870-947. 